\title{
Effect of ACE Inhibitors on Endothelial Dysfunction: Unanswered Questions and Implications for Further Investigation and Therapy
}

\author{
Bertram Pitt \\ University of Michigan School of Medicine, Ann Arbor, MI, USA
}

\begin{abstract}
Summary. Experimental studies have suggested that angiotensin-converting enzyme (ACE) inhibitors may have an important role in blocking the progression of and/or reversing endothelial dysfunction. The extrapolation of these experimental studies to the clinical situation has, however, been disappointing. Studies of forearm-mediated endothelial vasodilatation in patients with hypertension with captopril, enalapril, and cilazapril have been negative. The finding of the Trial in Reversing Endothelial Dysfunction (TREND) that the administration of quinapril to normotensive patients with coronary artery disease in part restores endothelial-mediated coronary vasodilation, as assessed by intracoronary administration of acetylcholine, has important implications for future therapy and raises several important questions. The differences in the TREND and previous studies of ACE inhibitors on endothelial dysfunction may be due to mechanistic differences in endothelial dysfunction in patients with coronary artery disease and hypertension. Although in general there has been a good correlation between endothelial dysfunction as assessed by forearm flow and coronary endothelial dysfunction as assessed by acetylcholine, these vascular beds may be affected differently by therapeutic interventions, especially with an ACE inhibitor, which may affect shear stress and angiotensin II formation in different vascular beds differently. Third, one needs to question whether the effect of quinapril on coronary endothelial dysfunction is a class effect or unique to quinapril. It will be necessary to test the effectiveness of other ACE inhibitors on coronary endothelial dysfunction in humans before concluding that the beneficial effects of quinapril are due to a class effect.
\end{abstract}

Cardiovasc Drugs Ther 1996;10:4:469-473

Key Words. endothelial dysfunction, ACE inhibitors, hypertension, coronary artery disease

Experimental studies in a variety of animal species, disease models, and with a variety of angiotensinconverting enzyme (ACE) inhibitors have suggested that ACE inhibitors may have an important role in blocking the progression of and/or reversing endothelial dysfunction [1-6]. These studies have far reaching implications for the therapy of a number of important disease entities, including atherosclerosis and its consequences, hypertension, heart failure, and possibly diabetes mellitus. Endothelial dysfunction is thought to be an early common pathway for these and other diseases involving the vascular wall [7]. The production and release of nitric oxide (NO) by the normal endothelium is essential for the vasodilator effect of a number of physiologic and pharmacologic mediators, prevents the adherence and infiltration of monocytes onto and into the vascular wall, as well as preventing the adherence and activation of platelets with subsequent thrombosis [7-10]. Thus, the finding in experimental studies that $\mathrm{ACE}$ inhibitors can prevent or reverse endothelial dysfunction has given hope to the prospect that these agents might have an effect on the natural history of several diseases that affect the vascular wall, beyond blood pressure reduction, prevention of left ventricular hypertrophy, and ventricular remodeling.

The mechanism by which ACE inhibitors prevent and/or reverse endothelial dysfunction is speculative. Angiotensin II has been shown to be an important oxidant $[11,12]$. At physiologic concentrations angiotensin II has been shown to increase the production of superoxide ions and lipid peroxidase, as well as to increase macrophage-mediated oxidation of LDL cholesterol [11]. Free radical formation can interfere with the formation and/or release of nitric oxide from the endothelium [13]. Angiotensin II causes the oxidation of LDL cholesterol and facilitates the migration of LDL cholesterol into the vascular wall independent of its oxidation [11,14]. Angiotensin II has also been shown to stimulate various cytokines that attract monocytes and their infiltration into the vascular wall with subsequent foam cell formation [15]. Angiotensin II has also been shown to cause the release of endothelin [16], which in itself is an important mitogen and vasoconstrictor. Angiotensin II alone or in combination with endothelin also causes vasoconstriction, an

Address for correspondence: Bertram Pitt, M.D., Division of Cardiology, University Hospital, 1500 East Medical Center Drive, Ann Arbor, MI 48109-0366, USA.

Received 29 March 1996; receipt/review time 32 days; accepted in revised form 1 May 1996 
increase in blood pressure, and shear stress, which could affect endothelial function [17]. ACE inhibitors, by blocking the formation of angiotensin II and/or by preventing bradykinin degradation, would tend to prevent these deleterious effects. Furthermore, ACE inhibitors have been shown to increase antioxidant defense mechanisms, such as superoxide dismutase [18], which would tend to prevent NO destruction.

The extrapolation of these experimental studies and theoretic considerations to the clinical situation has, however, been disappointing. For example, Creager and Roddy, in a study of patients with hypertension and endothelial dysfunction, could not demonstrate a beneficial effect of either captopril or enalapril administered for a 2 month period on endothelialdependent forearm vasodilatation [19]. Similarly, Kiowski et al, could not demonstrate a beneficial effect of the ACE inhibitor cilazapril on endothelial-dependent forearm vasodilatation in patients with hypertension treated for 20 weeks [20]. Although the acute administration of captopril has been reported to reverse endothelial dysfunction in hypertensive patients [21] this study was done during the administration of the drug, while the studies by Creager and Roddy [19] and Kiowski et al. [20] were done after drug withdrawal to examine whether chronic drug administration had altered vascular structure and/or function.

In view of these negative studies of chronic ACE inhibition in humans, it is of interest to find that the ACE inhibitor quinapril administered for 6 months to nonhypertensive patients with coronary artery disease and endothelial dysfunction resulted in a significant reversal of coronary artery endothelial dysfunction. The Trial in Reversing Endothelial Dysfunction (TREND) studied the effect of quinapril $40 \mathrm{mg}$ daily or placebo in 105 patients with coronary artery disease who at baseline coronary arteriography had demonstrable endothelial dysfunction, as evidenced by a loss of vasodilatation to the intracoronary administration of acetylcholine [22]. The patients in this study all had single or double-vessel coronary artery disease ( $>50 \%$ diameter stenosis), requiring nonsurgical revascularization and one adjacent major coronary artery with $<40 \%$ diameter stenosis that had not been revascularized. Endothelial dysfunction had to be present in the adjacent coronary artery $(\mathrm{a} \geq 5 \%$ reduction in mean lumen diameter or no response to acetylcholine) to be included. Patients with a history of hypertension could be included if they were controlled with a systolic blood $<160 \mathrm{mmHg}$ and a diastolic pressure of $<90 \mathrm{mmHg}$. At the end of the 6 month follow-up period, the study drug was withdrawn for 3 days and endothelial dysfunction was reevaluated by intracoronary acetylcholine. Patients randomized to quinapril were found to have had a significant improvement in endothelial dysfunction of $12 \%$ compared with $0.8 \%$ at a dose of $10^{-4} \mathrm{ml} / \mathrm{l}$ of acetylcholine in those randomized to placebo $(\mathrm{p}=0.002)$, without any significant effect of quinapril on systemic blood pressure.

Virdis et al. [23] have also shown that captopril $50 \mathrm{mg}$ bid administered for 1 year to 16 patients with essential hypertension and angiographically normal coronary arteries, and then withdrawn for 2 weeks, improved forearm blood flow in response to acetylcholine infusion in a subset of eight patients who had a positive dipyridamole echocardiographic stress test, suggestive of microvascular coronary artery disease. They also found a baseline abnormality in forearm blood flow to the endothelialindependent vasodilator nitroprusside, as well as an improvement in forearm flow in response to nitroprusside after the year of therapy with captopril. This data suggests an improvement in vascular structure as a result of effective antihypertensive therapy rather than a change in endothelial function perse. A reversal of vascular structural abnormalities in patients with hypertension has been previously seen in patients treated with an ACE inhibitor [24] as well as a calcium channel blocking agent [25]. Although there may have been a structural change in the coronary vessels of patients in the TREND [22] study, they had a vasodilator response to nitroglycerin at baseline and did not show a change in their response to nitroglycerin after therapy with quinapril, suggesting that the primary effect of quinapril in this situation, in contrast to the study by Virdis et al. [23], was a change in endothelial function.

The positive findings in the TREND study in regard to an improvement in endothelial function in patients with coronary artery disease treated with quinapril compared with the negative findings in patients with hypertension treated with captopril, enalapril, and cilazapril $[19,20,23]$, raise several important questions that will need to be answered before the data from the TREND study [22] can be placed in proper prospective.

First, the patients in the TREND study [22] all had angiographically proven coronary artery disease, whereas those in the studies by Creager et al. and Kiowski et al. $[19,20]$ had hypertension without known coronary artery disease, and the patients studied by Virdis et al. had angiographically normal coronary arteries. While endothelial dysfunction has been found in most patients with hypertension, it is not found in all patients [26], whereas the situation in patients with angiographic evidence of atherosclerotic coronary artery disease appears to be more homogenous [27-29]. It is possible that endothelial dysfunction in patients with hypertension is in some way mechanistically different from that in early atherosclerosis. Shear stress may affect endothelial dysfunction and vessel structure quantitatively or qualitatively differently than lipid and/or other coronary risk factor-induced endothelial dysfunction. For example, 
it could be postulated that oxidized LDL cholesterol and subsequent free radical formation might be more important in atherosclerosis-induced endothelial dysfunction, while shear stress may be the critical factor in patients with hypertension without the accumulation of LDL cholesterol in the vascular wall and that a reduction in blood pressure, rather than a reduction in LDL cholesterol, might be more important in this situation. Hypertension and atherosclerosis could also have quantitative and or qualitatively different effects on the formation, release, or effect of $\mathrm{NO}$ on smooth muscle cells.

Second, the studies by Creager and Roddy [19], Kiowski et al. [20], and Virdis et al. [23] focused on forearm-mediated endothelial dysfunction, while the TREND study [22] examined coronary endothelial dysfunction. In general, there has been a good correlation between endothelial dysfunction assessed by forearm flow and coronary endothelial dysfunction [27]. However, the endothelium in different vascular beds and in different sized arteries has been shown to differentially modulate the local conversion of angiotensin (AT) I to AT II [28]. Thus, it is possible that different vascular beds and segments within a vascular bed respond differently to different therapeutic interventions depending upon local ACE concentration and differential effects of the intervention on local shear stress. While it is convenient to study brachial artery endothelial dysfunction, one should be cautious in any extrapolation to other vascular beds without a careful prospective study of each intervention, especially with an ACE inhibitor which may affect shear stress and AT II formation in different vascular beds differently.

Third, one needs to question whether the effect demonstrated on the coronary endothelium by quinapril is a class effect of ACE inhibitors or is unique to quinapril or a particular group of $\mathrm{ACE}$ inhibitors. Quinapril is lipophilic and has been shown to be tightly bound to vascular ACE [32]. While on the basis of animal experiments one might predict that both lipophilic ACE inhibitors such as ramapril [3] and relatively hydrophilic ACE inhibitors such as enalapril [4], as well as sulfhydro-containing [2] and nonsulfhydro-containing $\mathrm{ACE}$ inhibitors [3] would be effective in humans, there may be important differences in the time and magnitude of their effectiveness. Thus, it will be necessary to test and demonstrate the effectiveness of other ACE inhibitors, such as the hydrophilic ACE inhibitors, on coronary endothelial dysfunction in humans before concluding that the beneficial effects of quinapril noted in the TREND study are a class effect.

While these and other more fundamental questions will need to be answered by careful prospective clinical research over the next several years, it is reasonable to predict that the results of the TREND study [22], if confirmed, will have important implications, at least for patients with coronary artery disease. One would anticipate that quinapril and possibly other similar ACE inhibitors will prove effective in preventing the development of new atherosclerotic lesions, progression of early atherosclerotic lesions, plaque rupture, and possibly thrombosis after plaque rupture, with a resultant decrease in ischemic events. A reversal of coronary endothelial dysfunction should also have an important effect on coronary vasomotor tone, with a consequent improvement in exercise and/or "silent" myocardial ischemia. Previous studies of ACE inhibitors have not, however, shown a uniform beneficial effect on angina pectoris. Cleland et al. [33], for example, found in fact that captopril increased the frequency of anginal episodes and use of nitroglycerin, possibly by inducing a coronary "steal." This and other studies testing the antiischemic effect of ACE inhibitors were, however, for the most part of relatively short duration, around 3 months. It may require longer term administration, possibly 6 months, before endothelial dysfunction is reversed as seen in the TREND study [22]. Conversely, as mentioned earlier, the ACE binding characteristics of quinapril [32] and possibly other lipophilic ACE inhibitors may make them unique. One might also postulate that the beneficial effects of quinapril on coronary endothelial dysfunction seen in TREND [22] would complement strategies such as LDL-cholesterol lowering. LDLcholesterol lowering by decreasing the potential for oxidation of LDL cholesterol has been shown to prevent and/or reverse endothelial dysfunction both in animals and humans [34-36]. The reversal of endothelial dysfunction by LDL-cholesterol reduction is associated with a significant decrease in new coronary artery lesion formation, progression of minimal coronary artery disease, and ischemic events [37-39]. These mechanisms, as mentioned earlier, are common to ACE inhibitors, and hence ACE inhibitors could be postulated to have a synergistic or additive effect to LDL-cholesterol lowering strategies as well as an independent effect in patients in whom LDL cholesterol is not elevated or pathophysiologically of importance.

Whether or not these predictions will prove accurate will in part be answered in the near future by ongoing large-scale prospective studies, such as QUIET [40], HOPE [41], and PEACE [42], in which the effect of ACE inhibitors on ischemic events and mortality are being investigated. Regardless of the outcome of these studies, it is likely that the provocative findings in the TREND study [22], in conjunction with previous experimental studies, will stimulate further basic and clinical investigation, and the likelihood that we will have a better understanding and possibly new opportunities for the secondary and possibly primary prevention of ischemic heart disease and other diseases affecting the vascular wall in which endothelial dysfunction appears to be an early common pathway. 


\section{References}

1. Becker RH, Wimer G, Linz W. Preservation of endothelial function by ramipril in rabbits on a long-term atherogenic diet. J Cardiovasc Pharmacol 1991;18:S110-S115.

2. Clozel M, Kuhn H, Hefti F, Baumgartner HR. Endothelial dysfunction and subendothelial monocyte macrophages in hypertension: Effect of angiotensin converting enzyme inhibition. Hypertension 1991;18:132-141.

3. Webb RC, Finto KM, Fisher M, Lee L, Pitt B. Ramipril reverses impaired endothelium dependent relaxation in arteries from rats fed an atherogenic diet. $F A S E B$ 1992;6: A1458.

4. Bossaller C, Auch-Schwelk W, Weber F, Gotze S, Grafe M, Graf K, Fleck E. Endothelium-dependent relaxation are augmented in rats chronically treated with the angiotensinconverting enzyme inhibitor enalapril. $J$ Cardiovasc Pharmacol 1992;20:S91-S95.

5. Dohi Y, Criscione L, Pfeiffer K, Luscher TF. Angiotensin blockade or calcium antagonists improve endothelial dysfunction in hypertension: Studies in perfused mesenteric resistance arteries. J Cardiovasc Pharmacol 1994;24:372379.

6. Mombouli JV, Nephtali M, Vanhoutte PM. Effects of the converting enzyme inhibitor cilazaprilat on endotheliumdependent responses. Hypertension 1991;18:II22-II29.

7. Vane JR, Anggard EE, Botting RM. Regulatory functions of the endothelium. $N$ Engl J Med 1990;323:27-36.

8. Palmer RMJ, Ferrige AG, Moncada S. Nitric oxide release accounts for the biological activity of endothelium-derived relaxing factor. Nature 1987;327:524-526.

9. Griffin SA, Brown WC, MacPherson F, et al. Angiotensin II causes vascular hypertrophy in part by a non-pressor mechanism. Hypertension 1991;17:626-635.

10. Vanhoutte PM. Endothelium and control of vascular function. State-of-the-art lecture. Hypertension 1989;13:658667.

11. Keidar S, Brook JG, Aviram M. Angiotensin II enhanced lipid peroxidation of low-density lipoprotein. Am Physiol Soc 1993;8:245-248.

12. Harrison DG, Ohara Y. Physiologic consequences of increased vascular oxidant stresses in hypercholesterolemia and atherosclerosis: Implications for impaired vasomotion. Am J Cardiol 1995;75:75B-81.

13. Griendling KK, Minieri CA, Ollerenshaw JD, Alexander RW. Angiotensin II stimulates NADH and NADPH oxidase activity in cultured vaseular smooth muscle cells. Cinc Res 1994;74:1141-1148.

14. Keidar S, Kaplan M, Aviram M. Angiotensin II-modified LDL is taken up by macrophages via the scavenger receptor, leading to cellular cholesterol accumulation. Arterioscler Thromb Vasc Biol 1996;16:97-105.

15. Farber HW, Center DM, Rounds S, Danilov SM. Components of the angiotensin system cause release of a neutrophil chemoattractant from cultured bovine and human endothelial cells. Eur Heart $J$ 1990;11:100-107.

16. Dohi $Y$, Hahn AWA, Boulanger CM, Buhler FR, Luscher TF. Endothelin stimulated by angiotensin II augments contractility of spontaneously hypertensive rat resistance arteries. Hypertension 1992;19:131-137.

17. Luscher TF, Raij L, Vanhoutte PM. Endothelium-dependent vascular responses in normotensive and hypertensive Dahl rats. Hypertension 1987;9:157-163.

18. deCavanagh EMV, Inserra F, Ferder L, Romano L, Ercole
L, Fraga CG. Superoxide dismutase and glutathione peroxidase activities are increased by enalapril and captopril in mouse liver. FEBS Lett 1995;361:22-24.

19. Creager MA, Roddy MA. Effect of captopril and enalapril on endothelial function in hypertensive patients. Hypertension 1994;24:499-505.

20. Kiowski W, Linder L, Nuesch R, Martina B. Effects of cilazapril on vascular structure and function in essential hypertension. Hypertension 1996;27:371-376.

21. Hirooka $\mathrm{Y}$, Imaizumi $\mathrm{T}$, Masaki $\mathrm{H}$, Aando $\mathrm{S}$, Harada $\mathrm{S}$, Momohera M, Takeshita A. Captopril improves impaired endothelium-dependent vasodilation in hypertensive patients. Hypertension 1992;20:175-180.

22. Mancini GBJ, Henry GC, Macaya C, et al. Angiotensin converting enzyme inhibition with quinapril improves endothelial vasomotor dysfunction in patients with coronary artery disease: The TREND Study (Trial on Reversing Endothelial Dysfunction). Circulation 1996, in press.

23. Virdis A, Ghiadoni L, Lucarinin A, DiLegge V, Taddei S, Salvetti A. Presence of cardiovascular structural changes in essential hypertensive patients with coronary microvascular disease and effects of long-term treatment. $A m J$ Hypertens 1995;9:361-369.

24. Dahlof B, Herlitz H, Aurell M, Hansson L. Reversal of cardiovascular structural changes when treating essentially hypertension. The importance of the renin-angiotensinaldosterone system. Am J Hypertens 1992;5:900-911.

25. Agabiti-rosei E, Muiesan ML, Rizzoni D, et al. Regression of cardiovascular structural changes after long-term antihypertensive treatment with the calcium antagonist nitrendipine. J Cardiovasc Pharmacol 1991;18:S5-9.

26. Cockcroft JR, Chowienczyk PJ, Benjamin N, Ritter JM. Preserved endothelium-dependent vasodilation in essential hypertension. N Engl J Med 1994;330:1029-1035.

27. Ludmer PL, Selwyn AP, Shook TL, et al. Paradoxical vasoconstriction induced by acetylcholine in atherosclerosis coronary arteries. $N$ Engl J Med 1986;315:1046-51.

28. Werns SW, Walton JA, Hsia HH, Nabel EG, Sanz ML, Pitt B. Evidence of endothelial dysfunction in angiographically normal coronary arteries of patients with coronary artery disease. Circulation 1989;79:287-91.

29. Zieber AM, Drexler H, Saurbier B, Just H. Effects of age, atherosclerosis, hypercholesterolemia, and hypertension: Endothelium-mediated coronary blood flow modulation in humans. $J$ Clin Invest 1993;92:652-62.

30. Anderson TJ, Uehata A, Gerhard MD, et al. Close relation of endothelial function in the humancoronary and peripheral circulation. I Am Coll Cardiol 1995;26:1235-1241.

31. Tang T, Connelly BA, Joycer WL. Heterogeneity of endothelial cell function for angiotensin conversion in serialarranged arterioles. $J$ Vasc Res 1995;32:129-137.

32. Johnston CI, Fabris B, Yamada H, Mendelsohn FAO, Cubela $R$, sivell D, Jackson B. Comparative studies of tissue inhibition by angiotensin converting enzyme inhibitors. $J$ Hypertens 1989;7:11S-16.

33. Cleland JG, Henderson E, McLenachan J, Findlay JN, Dargie HJ. Effect of captopril, an angiotensin-converting enzyme inhibitor in patients with angina pectoris and heart failure. J Am Coll Cardiol 1991;17:733-739.

34. Harrison DG: Endothelial dysfunction in atherosclerosis. Basic Res Cardiol 1994;89:87-102.

35. Harrison DG, Ohara Y: Physiologic consequences of increased vascular oxidant stresses in hypercholesterolemia and atherosclerosis: Implications for impaired vasomotion. Am J Cardiol 1995;75:75B-81. 
36. Treasure CB, Klein JL, Weintraub WS, et al. Beneficial effects of cholesterol-lowering therapy on the coronary endothelium in patients with coronary artery disease. $N \mathrm{Engl}$ $J$ Med 1995;332:481-487.

37. Pitt B, Mancini GBJ, Ellis SG, Rosman HS, Park JS, McGovern ME. Pravastatin limitation of atherosclerosis in the coronary arteries (PLAC I): Reduction in atherosclerosis progression and clinical events. J Am Coll Cardiol 1995; 26:1133-1139.

38. Byington RP, Jukema JW, Salonen JT, et al. Reduction in cardiovascular events during pravastatin therapy pooled analysis of clinical events of the pravastatin atherosclerosis intervention program. Circulation 1995;92:2419-2425.

39. Scandinavian Simvastatin Survival Study Group. Randomi- sed trial of cholesterol lowering in 4444 patients with coronary heart disease: The Scandinavian Simvastatin Survival Study (4S). Lancet 1994;344:1383-1389.

40. Texter M, Lees RS, Pitt B, Dinsmore RE, Uprichard ACG. The quinapril ischemic event trial (QUIET) design and methods: Evaluation of chronic ACE inhibitor therapy after coronary artery intervention. Cardiovasc Drugs Ther 1993; 7:273-282.

41. Lonn EM, Yusuf S, Jha P, Montague TJ, Teo KK, Benedict CR, Pitt B. Emerging role of angiotensin-converting enzyme inhibitors in cardiac and vascular protection. Circulation 1994;90:2056-2069.

42. Pfeffer MA. ACE inhibition in acute myocardial infarction. N Engl J Med 1995;332:118-120. 